\title{
ГЕНЕЗИС ВНЕШНЕЙ ПОЛИТИКИ США: ПОДХОД ОБЩЕСТВЕННОГО МНЕНИЯ Т.Э. БЕЙЛИ
}

\section{THE GENESIS OF US FOREIGN POLICY: T.A. BAILEY'S PUBLIC OPINION APPROACH}

\section{Dorofeiev}

Summary: The purpose of the study is to determine the role and place of the theme of the US foreign policy genesis in the views of T. A. Bailey in the context of the evolution of the diplomatic history school during the 1930-1970s and the approach of public opinion developed by him. The scientific novelty lies in the fact that for the first time the analysis of T.A. Bailey's approach to the topic of the origin of the foreign policy of the United States is carried out; its influence on the development of the topic in historiography is determined. The results of the study showed that under the influence of the progressive trend, T.A. Bailey laid and contributed to the systemic transformation of the school of diplomatic history; the topic of the origin of foreign policy was not highlighted by him, but he created the prerequisites for its actualization by revisionist historians in the 1940-1970s.

Keywords: genesis of foreign policy, historiography, revisionism, USA, S.F. Bemis, T.A. Bailey.

\section{Введение}

одход общественного мнения как теоретический вклад профессора Стэндфордского университета

Томаса Эндрю Бейли (1902-1983) в изучение истории внешней политики США получил многоаспектное рассмотрение в историографии. Однако общей тенденцией для исследователей второй половины XX в. и первой четверти XXI в. стала концентрация их внимания на изучении взглядов ученого на исторические процессы после 1789 г. [1, р. 1-20; 2, р. 1-18; 3, р. 1-27; 4, р. 1-32; 5, р. $1-17 ; 6$, p. $1-43 ; 13$, p. $1-37 ; 14$, p. $1-27 ; 17$, p. $2-21 ; 18$, p. 1-17; 24, p. 1-43]. В результате, сложился неизученный аспект творчества ученого: взгляд Т.Э. Бейли на зарождение внешней политики Соединённых Штатов сквозь призму подхода общественного мнения остается вне научного осмысления. Выявленное состояние историографии обуславливает актуальность проведения отдельного изыскания в этой сфере для заполнения пробела в академическом знании.

Исходя из состояния историографии, цель исследовательской работы заключается в том, чтобы определить роль и место темы генезиса внешней политики США во взглядах Т.Э. Бейли в контексте эволюции школы ди-
Дорофеев Денис Владимирович

К.полит.н., дочент, Крымский федеральный университет имени В.И. Вернадского, Симферополь dorof-denis@yandex.ru

Аннотация: Цель исследования - определить роль и место темы генезиса внешней политики США во взглядах Т.Э. Бейли в контексте эволюции школы дипломатической истории на протяжении 1930-1970-х гг. и разработанного им подхода общественного мнения. Научная новизна заключается в том, что впервые проведен анализ подхода Т.Э. Бейли к теме зарождения внешней политики Соединённых Штатов; определено его влияние на развитие темы в историографии. Результаты исследования показали: под влиянием прогрессистского направления Т.Э. Бейли заложил и способствовал системной трансформации школы дипломатической истории; тема генезиса внешней политики США им не была выделена, но он создал предпосылки для ее актуализации историками-ревизионистами в 1940-1970-е гг.

Ключевые слова: генезис внешней политики, историография, ревизионизм, США, С.Ф. Бимис, Т.Э. Бейли.

пломатической истории на протяжении 1930-1970-х гг. и разработанного им подхода общественного мнения. Следуя логике целеполагания, задачами исследования выступают: 1) проанализировать эволюцию интеллектуальной биографии Т.Э. Бейли на рубеже 1920-х и 1930-х гг. в контексте его перехода из прогрессистского направления в школу дипломатической истории; 2) выделить системные предпосылки формирования подхода общественного мнения Т.Э. Бейли, а также рассмотреть его применение ученым к теме генезиса внешней политики США во второй половине 1930-х и начале 1940-х гг.; 3) определить влияние подхода общественного мнения Т.Э. Бейли на эволюцию темы зарождения внешней политики Соединённых Штатов в историографии второй половины 1940-х - 1970-х гг.

Методология исследования построена на основе биоисториографической модели, состоявшей из комбинации биографического, историко-сравнительного, историко-генетического методов, системного подхода и принципа историзма. Поскольку концепция работы включает в себя интеллектуальную историю, то в исследовании уделяется ключевое внимание автобиографическим источникам Т.Э. Бейли, которые требуют использования метода критического анализа. 
Практическая значимость исследования заключается в возможности использовать его результаты и материалы в научно-педагогической деятельности: проведение исследований по историографии и истории внешней политики США, разработка учебных дисциплин по американистике.

\section{Интеммектуальная биография Т.Э. Бейли на рубеже 1920-х - 1930-х гт.: перехо к изучению внешней политики}

В процессе обучения в Гарвардском университете Т.Э. Бейли защитил докторскую диссертацию на тему «История партийных нарушений в Сенате Соединённых Штатов 1869-1901 гг.» (1927) [8] и совершенно не специализировался на внешней политике. Спустя годы он отметит упущения в образовании откровенным признанием: «Мое формальное образование в области дипломатической истории, да и вообще всей истории, было неудачным. <...> Цена, которую я, в конечном счете, заплатил за свое неверно направленное образование, заключалась в том, что мне пришлось формировать свою дипломатическую историю и вспомогательные дисциплины самостоятельно» [10, р. 3-4].

Стечения обстоятельств привели молодого ученого в новое для него исследовательское поле. Интерес к внешнеполитической сфере появился у него во время преподавательской деятельности на должности доцента истории и политологии в Гавайском университете [11, p. 92]. Т. Э. Бейли в мемуарах объяснял свой переезд на архипелаг карьерными причинами: преподавая в Колледже Сан Матео (колледж низшей ступени), он был недоволен низким статусом учебного заведения, поэтому, когда ему попалась информация о вакансии, сразу же согласился, поскольку поступал на работу в вуз, где мог бы преподавать на более высоком уровне. При этом, как он отмечал: «Никто на материке, казалось, не хотел этого (трудоустройства. - Д.Д.), и некоторых потенциальных сотрудников спрашивали, кого бы они порекомендовали, если бы их не привлекла эта должность» [lbid.].

Доступ к местным архивам Т.Э. Бейли помог получить коллега по историческому факультету - Ральф Симпсон Куйкендалл (1885-1963), преподаватель истории, секретарь Гавайского исторического общества с 1922 г. по 1932 г., но, самое главное, он, как и новоприбывший историк, был тоже учеником профессора Герберта Юджина Болтона (1870-1953) [22, р. 56]. Неформальные связи внутри т.н. «болтоновской школы» открывали перспективные возможности осуществлять академическую мобильность.

Имея доступ к первоисточникам, Т.Э. Бейли сделал шаги в новой сфере, выбрав проблематику международного аспекта американской аннексии Гавайского королевства [19, р. 42]. С этих публикаций началась новая веха в научной карьере Т.Э. Бейли, снискавшего авторитет историка-ревизиониста, развенчивавшего мифы [21, р. 52-53]. Характерной особенностью этого периода было то, что ученый обратил внимание на роль печатных изданий - газет - в качестве источника для проведения анализа внешней политики. Ограниченность количества официальных источников им компенсировалась привлечением газетного материала. В перспективе это решение будет иметь далеко идущие последствия для развития науки.

Оставаться в изоляции от материка ученый не собирался и пытался использовать любую возможность, чтобы вернуться. Она появилась только спустя три года. Процесс «возвращения» не был случайностью, а представлял собой результат протекции его куратора по студенческим годам - профессора Эдгара Юджина Робинсона (1887-?). Стараниями наставника Т.Э. Бейли получил место работы в Стэндфордском университете [16, р. 162-163]. Оказавшись в совершенно другой интеллектуальной среде, молодой ученый окончательно решил связать свои научные изыскания с историей внешней политики США. Этому решению способствовала не только работа в престижном вузе, но и членство в Тихоокеанском отделении Американской исторической ассоциации. В совокупности вуз и профессиональная организация создавали системные условия для роста, но требовали и специализации на конъюнктурных темах. Тем не менее, на протяжении 1930-х гг. Т.Э. Бейли не вел научных разработок по проблематике раннего периода внешней политики США, отдавая предпочтение современной истории. Одновременно, он отходил от «узкого» понимания истории дипломатии, основанного на официальных источниках.

\section{Системные предпосылки формирования по $\Delta х о \Delta а$ обшественного мнения и тема зарожАения внешней политики США во взгляАах Т.Э. Бейли (вторая половина 1930-х - начало 1940-х гг.)}

Радикальные изменения произошли во второй половине 1930-х гг.: «карантинная речь» от 5 октября 1937 г. президента Ф.Д. Рузвельта обозначила резкие перемены во внешней политике США - неизбежность вовлечения страны в международные отношения надвигавшейся Второй мировой войны. Перемены требовали изменения общественного мнения. Прежний концепт, разработанный профессором Йельского университета Сэмюелем Флэггом Бимисом (1891-1973), отображал преобладание изоляционистских настроений в первой половине 1930-х гг. Приближение конфликта и неизбежность участия в нем США создавали предпосылки для поиска новой парадигмы коммуникаций между правящей элитой и обществом - сказывался негативный опыт президента Томаса Вудро Вильсона, утратившего связь с электоратом. 
Меняющийся контекст общественно-политического дискурса второй половины 1930-х гг. привел к поиску новой модели подачи исторического материала, в котором, как у С.Ф. Бимиса, не делался акцент на американской исключительности и уникальности и в котором противопоставлялись США и Европу. Политическая повестка привела к тому, что одними из выразителей нововведений стал Т.Э. Бейли. Наиболее значимые плоды этого выбора проявились уже в годы войны и были связаны с публикацией ряда книг, среди которых два издания отображали его взгляды на генезис внешней политики североамериканского государства. Обе книги представляли собой не академические, а учебные издания - для охвата большей аудитории читателей.

На рубеже 1939-1940 гг. вышла в свет монография «Дипломатическая история американского народа». Название было заимствовано из заголовка книги Джона Баха Макмастера (1952-1932) «История народа Соединённых Штатов: от революции до Гражданской войны» $[10$, р. 6]. По словам Т.Э. Бейли замысел сочинения рождался из практики, а также под влиянием примера педагогического опыта коллеги по университету - профессора Самуэля Элиота Морисона (1887-1976), который вел активную публикационную деятельность по написанию учебной литературы для студентов [11, р. 68]. «Почти десять лет - отмечал Т.Э. Бейли - я читал курс лекций по истории американской дипломатии в Стэнфорде и не пользовался учебником. Имелось несколько довольно хороших книг, но тогдашний заведующий нашим отделом, писавший трудную прозу, был недружелюбен к непереваренной истории. В конце концов я решил включить свой основной лекционный материал в книгу “Дипломатическая история американского народа", впервые опубликованную в 1940 году» [lbid, p. 69].

Т.Э. Бейли утверждал, что его работа была написана на основе хронологического, а не тематического подхода, а факты замещались интерпретацией. Стиль изложения был упрощен, поскольку он был обращен к студенческой аудитории, а рецензенты, принадлежавшие к более старшему поколению, негодовали о целесообразности публикации. Эта ситуация была малоприятной для ученого даже по прошествии десятилетий: «Чувствуя себя по-юношески неуверенно и сознавая всепроникающую опасность ошибок, послал одну-две главы рукописи нескольким друзьям-профессионалам для получения их критической реакции. Большинство ответов были полезными, но два респондента старой гвардии нахмурились на очевидную попытку молодого хлыща в возрасте около тридцати лет привнести некоторую степень бодрости в обычно скучную тему. Один пожилой профессор Калифорнийского университета в Беркли настойчиво увещевал меня не публиковать книгу, написанную в этом духе: я погублю свою репутацию ученого еще до того, как она у меня появится. Выдающийся специ- алист по Каслри из Кембриджского университета, с которым я познакомился летом в Стэнфорде, вернул мою главу о доктрине Монро без сопроводительного письма или комментария, за исключением единственной фразы, написанной крупными буквами на первой странице, "Я не верю, что история может быть написана таким небрежным способом"» [10, р. 6]. «Приземленный» стиль книги, по мнению профессора Рэймонд Г. О'Коннор, был следствием корреляции между уровнем образования в стране и лингвистическим способом изложения материала: «Бейли обвинили в том, что он апеллирует к наименьшему общему знаменателю, чтобы пробудить интерес студентов, но количество внедрений, впечатляющие продажи и последовавшие издания было красноречивым свидетельством состояния образования в этом государстве» [23, р. 304].

Для самого Т.Э. Бейли стиль не был первостепенным фактором, поскольку свою книгу он видел в качестве альтернативы работам С.Ф. Бимиса. По его мнению, в отличие от своего коллеги, им выражалась идея фундаментальности роли общественного мнения в формировании внешней политики США, которую следовало рассматривать в качестве определяющего фактора в анализе исторического процесса [7, p. iii]. Сравнивая книги, Т.Э. Бейли писал: «Я никогда не утверждал, что моя дипломатическая история была лучше, чем у Бимиса. Мы делали две разные вещи, и никто не может осмысленно сравнить бифштекс с яблочным пирогом. Он писал историю в традиционном стиле, с точки зрения Государственного департамента и канцелярии (Белый дом. - Д.Д.). Я пытался рассказать основную историю с точки зрения людей, которые ее прожили и создали; отсюда и Дипломатическая история американского народа. Человеческая комедия живее, чем сюртуковые бригады, и для большинства читателей интереснее» [12, р. 17].

Тем не менее, исследование книги - особенно глав «Колониальный фон» и «Дипломатия французского альянса, 1775-1778» - показало: во-первых, анализ общественного мнения, как предмет, отсутствует, не смотря на его декларирование автором [7, р. 19-51]; вовторых, нет ни нового взгляда, ни новых фактов, которые не встречались в ранее изданных работах 1890-х - 1930X гг. Из работ авторов первой трети XX века, особенно С.Ф. Бимиса, на которого Т.Э. Бейли делал сноски, заимствована идея о том, что колониальный опыт определял внешнюю политику США после 4 июля 1776 г., а само новое государство оказалось во враждебных ему международных отношениях [lbid., p. 18-23]. Тезис об эмбриональном состоянии внешней политики в колониальный период истории США, когда сформировались такие элементы, как изоляционизм, принцип двух полушарий, невмешательство в чужие войны, свобода морей, свобода торговли, мирное урегулирование международных споров - был заимствован Т.Э. Бейли из статьи «Колони- 
альное происхождение американских дипломатических принципов» своего коллеги по Стэндфордскому университету - профессора Максвелла Хикса Сэвейлла (18961979) [lbid., p. 24].

Сам автор пояснял заимствования простыми причинами: «Я никогда не думал о "Дипломатической истории" как об обычном учебнике, хотя он и используется для этой цели. Моя концепция текста - это безжизненная, нагруженная фактами мини-энциклопедия, полностью или почти полностью основанная на второстепенных работах. Я слышал о писателях учебников, которые внесли свой "оригинальный" вклад, создав три или четыре конкурирующие книги и подготовив синтез, который не дал большего результата, чем содержание источников. Мой план состоял в том, чтобы создать оригинальное исследование, с тремя или четырьмя сносками на странице $<\ldots>$ » $[10$, p. 5-6].

Спустя три года, в 1943 г., вышла вторая книга «Внешняя политика Америки: прошлое и настоящее» [9, р. 7-10; 21, р. 70]. Обстоятельства возникновения книги Т.Э. Бейли объяснял конъюнктурой Второй мировой войны: «Несомненно, в результате моей “Дипломатической истории", опубликованной в 1940 году, Ассоциация внешней политики попросила меня подготовить одну из своих "Книг с заголовками", фактически брошюру на 96 страницах. Она называлась "Американская внешняя политика: прошлое и настоящее" и должна была стать сокращенной версией моей более длинной книги, изложенной в легко понятных непрофессионалу терминах. Проработав так долго над огромным полотном, я опасался, что у меня возникнут проблемы с трактовкой предмета в микрокосме, но задача решилась гораздо быстрее, чем я ожидал, и брошюра появилась в 1943 году. Было напечатано довольно много экземпляров; я припоминаю, что около 100000 единиц было выпущено специальным изданием для использования Вооруженными силами» [11, р. 153].

Издания Т.Э. Бейли сочетались с работами С.Ф. Бимиса, поскольку имели общее предназначение: книги использовались для формирования консенсуса внутри общества о новом статусе США в международных отношениях и вере в незыблемость демократических ценностей. Также Т.Э. Бейли пытался противостоять теориям о заговоре правящих элит в механизме принятия внешнеполитических решений, указав на роль демократических практик, учитывавших общественное мнение [lbid., p. 128]. Также ученый противостоял попыткам вернуть страну к изоляционизму. В частности, это привело к конфликту с историком-прогрессистом, ярым поборником политики невмешательства профессором Ч.О. Бирдом (1874-1948). Т.Э. Бейли описал этот инцидент в мемуарах: «В должное время я послал рукопись (книга «Внешняя политика Америки: прошлое и настоящее» - Д.Д.), кото- рая была передана на рецензирование доктору Чарльзу О. Бирду. Этот искусный полемист, в течение некоторого времени пребывавший в крайнем изоляционистском настроении, был настроен против президента Рузвельта за успешное втягивание страны в войну с помощью того, что многие считали окольными путями. Бирд предложил внести в рукопись ряд изменений, которые соответствовали бы его собственным изоляционистским взглядам, но я отказался их принять» [lbid., p. 153].

По мнению профессора Александра Деконда (19202016) - ученика Т.Э. Бейли - его наставник, хотя и ассоциировался с прогрессисткой школой, но с С.Ф. Бимисом его объединяло то, что они оба имели близкие взгляды и писали работы в контексте американского национализма [15, р. 9]. В действительности, оба ученых были связаны не национализмом, а участием в работе школы дипломатической истории, которая получила поддержку от правительственных структур: и С.Ф. Бимис, и Т.Э. Бейли были кооптированы в работу государственных институтов, особенно, Государственного департамента [25, p. 205-206].

\section{В^ияние взгляАов Т.Э. Бейли на эволюшию темы генезиса внешней политики США в историографии (вторая половина 1940-х - 1970-е гт.)}

Несмотря на то, что Т.Э. Бейли сформулировал подход общественного мнения, во время Второй мировой войны он дополнял концепт С.Ф. Бимиса. Но уже после завершения конфликта, со второй половины 1940-х гг., соотношения между взглядами двух ученых претерпели трансформацию: медленное угасание националистической интерпретации С.Ф. Бимиса сопровождалось растущим ревизионизмом в исторической науке. Одним из идейных вдохновителей процесса переоценки историописания внешней политики США выступил Т.Э. Бейли: его подход стал питательной почвой для формирования нового поколения историков-ревизионистов, которые трансформировали школу дипломатической истории, лишив ее националистической доминанты. Не только взгляды, но и прямая поддержка Т.Э. Бейли стояли за действиями его ученика - А. Деконда, стараниями которого происходил процесс деполитизации школы дипломатической истории, была создана профессиональная организация - Общество для историков американских внешних отношений. Фактически, подход Т.Э. Бейли, обративший внимание на внутренние истоки внешней политики, связанные с обществом, послужил толчком к поиску новых источников и методологий.

Трансфер из прогрессистского направления в школу дипломатической истории дал возможность Т.Э. Бейли сформировать не только новый взгляд на источники, но и сместить фокус анализа с государственных инсти- 
тутов на социум. Подход общественного мнения послужил толчком к изменению отношения к анализу истории внешней политики как раннего периода, так и современности. Будучи распространенным в годы Второй мировой войны с целью консолидации общества и правящих элит, подход Т.Э. Бейли принес неожиданный результат в науке уже во второй половине 1950-х гг.: на нем сформировалось поколение историков-ревизионистов в школе дипломатической истории, которые отошли от «узкого» анализа внешней политики на основе официальных документов, отдав предпочтение концепту международной истории, предполагавшей проводить анализ культуры, а не государственных институтов, при рассмотрении внешней политики Соединённых Штатов. Кроме того, наработки ученого на протяжении 1960-1970-х гг. вышли за пределы школы дипломатической истории, став одним из компонентов методологии «Новых левых», «Висконсинской школы дипломатической истории» [20, p. 311].

Таким образом, Т.Э. Бейли стоял у истоков тектонического сдвига в методологии анализа внешней политики, в целом, и создании системных предпосылок для развития темы генезиса внешней политики. Без новаторского взгляда ученого, преодоление государство-центризма в американской науке 1960-1970-х гг. имело бы другой путь развития.

\section{Зак^ючение}

На рубеже 1920-1930-х гг. Т.Э. Бейли перешёл из прогрессистского направления в школу дипломатической истории. Интеллектуальная биография ученого показала последствия этого процесса: он пришел к отказу от ограничения источниковой базы исследований только официальными документами, видя альтернативу, например, в газетных материалах; обосновал смещение объекта анализа с государства на общество при изучении внешней политики.

Свёртывание изоляционистских приоритетов во второй половине 1930-х гг. в общественно-политическом дискурсе США заложило системные предпосылки для аккумуляции наработок Т.Э. Бейли в подходе общественного мнения при анализе внешней политики, согласно которому она осуществляется исключительно в соответствии с позицией американского общества. Изучение позиции ученого в публикациях начала 1940-х гг. относительно темы генезиса внешней политики США выявило парадоксальную ситуацию. Несмотря на декларацию постулата об основополагающем факторе мнения американцев при формировании внешнеполитического курса страны с 1776 г., Т.Э Бейли не рассмотрел период до 1789 г., в целом, и тему генезиса внешней политики, в частности. Произошедшее было результатом незавершенности построения теоретической части подхода; следствием отсутствия самостоятельного изучения источников последней трети XVIII века

Тем не менее, и подход, и сам историк стали источниками ревизионизма в школе дипломатической истории со второй половины 1940-х до конца 1970-х гг. В рамках этого процесса произошла актуализация темы генезиса внешней политики Соединённых Штатов, рассмотрение которой происходило на основе новой исследовательской парадигмы, базировавшейся на социально ориентированном приоритете и привлечении неофициальных источников.

\section{ЛИТЕРАТУРА}

1. A companion to American Foreign Relations / ed. by Robert D. Schulzinger. - Malden: Blackwell Pub., 2008. - 577 p.

2. A companion to U.S. foreign relations: colonial era to the present: in 2 vols. Vol 1 / ed. by Christopher R. Dietrich. - Chichester: Wiley Blackwell, 2020. - 546 p.

3. America in the world: the historiography of American foreign relations since 1941 / ed. by Michael J. Hogan. - New York: Cambridge University Press, 1995. $619 \mathrm{p}$.

4. America in the world: the historiography of American foreign relations since 1941 / ed. by Frank Costigliola, Michael Hogan. - Cambridge: Cambridge University Press, 2014. $-376 \mathrm{p}$.

5. American foreign policy: a history: in 2 vols. Vol. 1: to 1914 / Thomas G. Paterson, J. Garry Clifford, Kenneth J. Hagan. - Lexington: D.C. Heath, 1988. - 255 p.

6. American foreign relations since 1600: a guide to the literature / ed. by Robert L. Beisner. - Santa Barbara: ABC-Clio, 2003. - 2065 p.

7. Bailey T.A. A diplomatic history of the American people. - Englewood Cliffs: Prentice-Hall, 1980. - 1093 p.

8. Bailey T.A. A history of party irregularity in the Senate of the United States 1869-1901. Ph.D. Thesis. - Leland: Stanford Junior University, 1927. - 298 I.

9. Bailey T.A. America's foreign policies: past and present / Thomas A. Bailey. - Millwood: Kraus Reprint, 1973. - 96 p.

10. Bailey T. A. Confessions of a diplomatic historian / Thomas A. Bailey // The Society for Historians of American Foreign Relations Newsletter. - 1975. - Vol. 6, №2. P. 2-11.

11. Bailey T.A. The American pageant revisited: recollections of a Stanford historian / Thomas A. Bailey. - Stanford: Hoover Institution Press, $1982 .-221 \mathrm{p}$.

12. Bailey T.A. The Friendly Rivals: Bemis and Bailey / Thomas A. Bailey // The Society for Historians of American Foreign Relations Newsletter. - 1979. - Vol. 10, №1. P. 12-17.

13. Bemis S.F. Guide to the diplomatic history of the United States, 1775-1921 / Samuel Flagg Bemis. - Washington: United States Government Printing 0 ofice, 1935. $-979 p$. 
14. Combs J.A. American diplomatic history: two centuries of changing interpretations / Jerald A. Combs. - Berkeley: University of California Press, $1986 .-413$ p.

15. DeConde A. New interpretations in American foreign policy / Alexander Deconde. - Washington: Service Center for Teachers of History, 1976. - $48 \mathrm{p}$.

16. Deconde A. Thomas A. Bailey: Teacher, Scholar, Popularizer / Alexander Deconde // Pacific Historical Review. - 1987. - Vol. 56, №2. - P. 161-193.

17. Explaining the history of American foreign relations / ed. by Frank Costigliola, Michael J. Hogan. - New York: Cambridge University Press, 2016. - 389 p.

18. Guide to American foreign relations since 1700 / ed. by Richard Dean Burns. - Canta Barbara: ABC-Clio, Inc., 1983. - 1311 p.

19. Kuykendall R.S. Historical notes / Ralph S. Kuykendall // Fortieth annual report of the Hawaiian Historical Society for the year 1931 / Hawaiian Historical Society. Honolulu: Honolulu Star-Bulletin, 1932. - P. 34-42.

20. Lafeber W. Fred Harvey Harrington / Walter Lafeber // Diplomatic History. - 1985. - Vol. 9, №4. - P. 311-319.

21. Langley L.D. The Diplomatic Historians: Bailey and Bemis / Lester D. Langley // The History Teacher. - 1972. - Vol. 6, №1. - P. 51-70.

22. Magnaghi R.M. Herbert E. Bolton and the historiography of the Americas / Russell M. Magnaghi. - Westport: Greenwood Press, 1998. - $211 \mathrm{p}$.

23. O'Connor R.G. Thomas A. Bailey: His Impact / Raymond G. O'Connor // Diplomatic History. - 1985. - Vol. 9, №4. - P. 303-309.

24. Paths to Power: The Historiography of American Foreign Relations to 1941 / ed. by Michael J. Hogan. - New York: Cambridge University Press, $2000 .-303$ p.

25. Tyrrell I. Historians in Public: The Practice of American History, 1890-1970 / lan Tyrrell. - Chicago: University of Chicago Press, 2005. - 348 p.

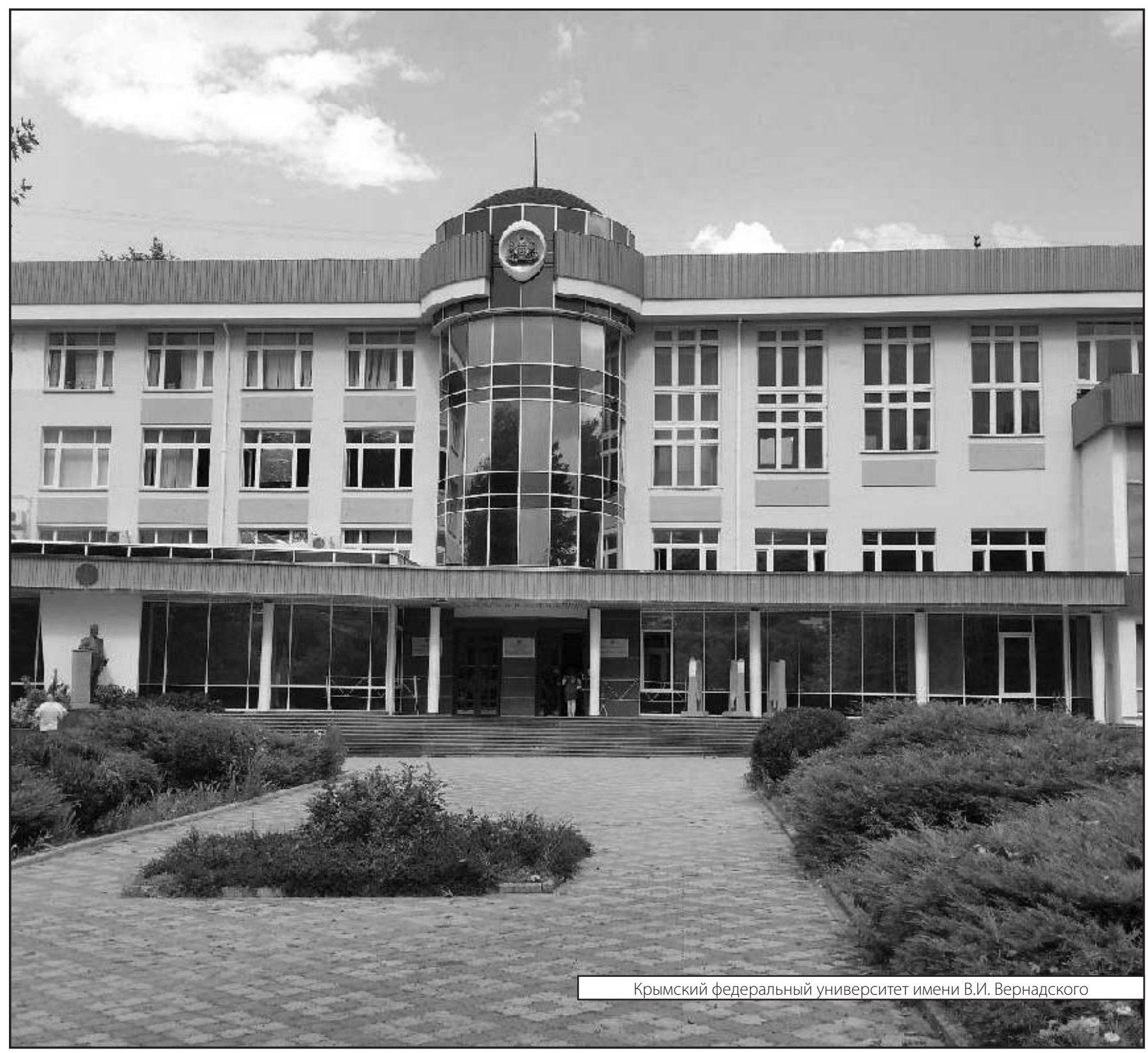

